\title{
INTRODUCTION
}

\section{Regional climate change in the NW Iberian Peninsula}

\author{
Luis Gimeno ${ }^{1, *}$, Ricardo M. Trigo ${ }^{2}$, Moncho Gómez-Gesteira ${ }^{1}$ \\ ${ }^{1}$ Environmental Physics Laboratory, Universidad de Vigo, Faculty of Sciences, Ourense, Spain \\ ${ }^{2}$ Instituto Don Luiz, Centro de Geofísica da Universidade de Lisboa, University of Lisbon, CGUL, IDL, Lisbon, Portugal
}

\begin{abstract}
In this CR Special we summarize the state of knowledge about the observed and future climate change in the NW Iberian Peninsula. In addition to describing the physical aspects of such climate changes, we also discuss their impacts on people, and how society responds, or should respond.
\end{abstract}

KEY WORDS: Regional climate change $\cdot$ NW Iberian Peninsula $\cdot$ Climate diagnosis $\cdot$ Modelling Resale or republication not permitted without written consent of the publisher

\section{Introduction}

Although climate change is a global problem, most of the solutions and necessary adaptations need to be taken at local and regional levels, where interaction amongst environment and human institutions occurs with the highest intensity. The objectives of this CR Special were to improve our understanding of climate change and its effects in the NW Iberian Peninsula - a region that is particularly sensitive to such changes. The articles in this CR Special describe climate change and its and causes, as well as discussing its effects on people, and the ways the society responds or should respond.

\section{Regional context}

The first paper of this special issue (Gómez-Gesteira et al. 2011) provides the context for the entire CR Special, with a large team of co-authors bringing together a wide range of expertise from different atmospheric and oceanographic sub-areas. The authors produced a comprehensive review on the observed changes of both atmospheric and marine trends characterising the NW Iberian Peninsula between the second half of the 20th century and early 21st century. Besides showing an upward trend in temperature and non-significant changes in precipitation, the authors provide evidence for significant decreases in oceanographic Ekman transport normal to the coast (upwelling index) since 1975, and a decline in runoff in the Miño River since 1970. These changes are explained in terms of changes in atmospheric circulation patterns at various scales, including the North Atlantic Oscillation.

\section{Observed or projected changes}

The 10 following papers present aspects concerning atmospheric or oceanic changes in the region and relevant surroundings areas.

\subsection{Atmospheric variables}

Global Climate Models (GCMs) are the most effective tools for generating climate projections, and their outputs are used in virtually all decision making in the fields of climate change adaption and mitigation. However, their ability to reproduce aspects of present day climate is imperfect, especially at small spatial and temporal scales, often requiring the application of additional modelling strategies to downscale to these smaller scales. Hence, Brands et al. (2011a) assessed the performance of 12 GCMs from 2 different model 
generations for southwestern Europe. Overall the Hadley Centre's HadGEM models were most effective for this specific region of the world.

In Brands et al. (2011b), daily temperatures were downscaled from an ensemble of GCM-control and scenario runs. Since for summer and autumn the fit between the distribution functions of observed and downscaled time series is nearly perfect, projections can be given relative to observations, and not to values downscaled from the control runs. Hence, the 'delta' method (usually used to take account of GCM errors in reproducing aspects of present-day climate) is avoided. The spread of the projections is dominated by model uncertainties, rather than forcing or initial-condition uncertainties. A tripling to quadrupling of extreme summer heat days is expected by the middle of the century.

Ramos et al. (2011) provide a complete assessment on changes in daily maximum and minimum temperatures over Portugal at a seasonal scale, showing that that the steepest increases for both measures are in spring and summer. The authors used 23 long-term series (1941-2006), and provide substantial evidence that the increment is mostly concentrated in the period since the 1970 s, while the previous decades were dominated by downward trends. The study provides projections for these variables at the end of the 21st century, as simulated by a regional climate model.

Drumond et al. (2011) identified the 2 dominant source regions contributing winter moisture in the NW Iberian Peninsula: the extended Bay of Biscay (BB) and the Tropical and Subtropical North Atlantic corridor (TSNA). While around $75 \%$ of the total TSNA winter contribution occurred during rainy days over Galicia and North Portugal (GALNP), a large part of the BB moisture contribution occurs under anticyclonic conditions, which are related to stable atmospheric conditions and inhibition of precipitation. Once dynamic conditions are favourable for generating precipitation, $\mathrm{BB}$ moisture appears to contribute to rainy days. Interannual variations of winter precipitation over GALNP may be directly related to the variability in the TSNA moisture contribution.

The study by Vicente-Serrano et al. (2011) shows the different effects that precipitation variability and warming processes have on drought severity and surface water resources. The results also indicate that precipitation has tended to increase in the region, and a significant increase has occurred in the potential evapotranspiration. In addition, although in the last 3 decades the mean duration of drought episodes has increased by approximately 1 mo as a consequence of evapotranspiration processes, surface water resource levels have mainly been driven by precipitation variability. The authors discuss the potential implications of global warming — as projected by GCMs - on future drought severity and the availability of water resources.

\subsection{Oceanic variables}

Santos et al. (2011) studied upwelling variability along the western coast of the Iberian Peninsula for the period 1948-2009. The Upwelling Index signal can be fitted to different functions with diametrically opposed results: (1) a weakening of upwelling intensity when both a simple linear regression and a fit to an equation including a linear term and a sinusoid were considered, and (2) a strengthening of upwelling intensity when a fit to a function including a linear term and a double sinusoid was considered.

Gago et al. (2011) conducted a monthly series (19942006) of CTD sampling in the Iberian upwelling system along a coastal-shelf transect in the Ría de Vigo and adjacent shelf, to analyze the spatial variability of the hydrographic processes over different timescales (seasonal and interannual). The authors show that the observed temperature increase is in accordance with corresponding changes in upwelling intensity and other climatic indices.

Pardo et al. (2011) studied the sea-surface temperature (SST) and upwelling index time series of the last 6 decades, showing a general warming and a weakening of the upwelling in the Iberian system, which are correlated with the NAO and EA indices. Studies on NW Africa show similar results. Comparisons with other oceanic upwelling systems revealed contrasting patterns.

Andrade et al. (2011) performed one of the first palaeoclimatic studies of NW Iberia, based on the relationship between the intensity of diagenetic processes and the origin of sedimentary organic matter. It is based on a multi-proxy study where geochemical, magnetic and texture data were used to identify changes in the intensity of early diagenetic processes that were triggered by changes in the ratio of oceanic and terrestrial organic matter inputs. The results identify periods of increased upwelling and reduced continental input due to colder, drier climatic conditions in the NW Iberian Peninsula, namely the Little Ice Age, the Dark Ages, and the first cold period of the Upper Holocene.

The study by Abrantes et al. (2011) uses sediments from a new core located close to Porto and the mouth of the River Douro (northern Portugal), used to reconstruct marine and continental conditions during the last millennium. The authors relate changes in SST and precipitation to results obtained by other authors, and show that the link they observed between these changes and North Atlantic Oscillation (NAO) patterns is probably modulated by solar variability. 


\section{Effects of climate change}

The last 6 papers of this CR Special are concerned with implications of regional climate change for phenological or biological variables, health, agricultural or socioeconomic aspects.

Adopting an agronomical and allergological perspective, Rodríguez-Rajo et al. (2011) study phenological event changes in trees at the edge of the Eurosiberian and Mediterranean regions. A trend towards increasing temperatures (especially in spring and summer) was particularly marked in the south of Galicia. This temperature increase causes a generally earlier onset of the pollen season and an advance in the end of the Castanea pollen season in the Mediterranean area.

The work by Bode et al. (2011) deals with the nutrient inputs (affecting oceanic primary production), which depend ultimately on atmospheric forcing. Increasing stratification due to by surface warming and changing wind patterns affecting coastal upwelling are among the factors most likely influencing nutrient inputs and therefore primary production in the ocean. Time series of both satellite-derived and in situ phytoplankton chlorophyll biomass and in situ primary production obtained in the upwelling ecosystem off NW Spain showed variable trends for the last 19 yr. Primary production increased in the western region (Galicia) and decreased in the east (Mar Cantábrico), in agreement with a multidecadal reduction in upwelling. However, these changes were not clearly correlated with an increase in stratification nor with large scale atmospheric pressure fields, in contrast to the changes observed in the open ocean.

Chust et al. (2011) review the effects of global climate change on the Basque coast and the pelagic systems of the southeastern Bay of Biscay. Climate projections under greenhouse gas emission scenarios indicate that this area will experience changes in climate throughout the 21st century, including: warming of surface air, intensification of extreme daily rainfall $(10 \%)$, warming of the upper $100 \mathrm{~m}$ of the ocean layer $\left(1.5\right.$ to $\left.2.05^{\circ} \mathrm{C}\right)$, and sea level rise $(29$ to $49 \mathrm{~cm})$. Observations undertaken in the bay throughout the 20th century for air temperature and mean sea level are in agreement with these projections. The main impacts on the coast are expected to be from sea level rise, especially in low-lying (mostly urbanised) areas of estuaries, and the retreat of sandy beaches (between 25 and $40 \%$ of their width).

The study by deCastro et al. (2011) evaluates the mortality effects of intense heatwaves in Galicia between 1987 and 2006. The authors show that above critical temperature thresholds - usually around the 95th percentile of the maximum - there is increased mortality in the elderly segment of the population (over
$65 \mathrm{yr})$. Interestingly the population in the region was more affected during the 1990 episode and not by the outstanding 2003 heat wave, despite the stronger intensity of the latter event.

Hanemann et al. (2011) use data from a 2009 phone survey, representative of the Spanish population, to calculate households' willingness to pay (WTP) for a green electricity program that is designed to foster noncarbon technologies. Their study attempts to explain the contrast between the scarce application of GHG pricing policies in Spain and the intense stated social preferences for climate change abatement. By showing a high average WTP (as compared with the current average electricity bill) for the green electricity program, the authors suggest that Spanish households may selectively support certain policies. They also indicate that younger individuals who live in the Mediterranean area are more likely to be willing to pay for this program.

Gouveia et al. (2011) evaluate the seasonal effects of several climate variables on driving factors of wine productivity in the Douro Valley region of Portugal. They show that lower precipitation in March has a generally positive effect (including growth and quality) during the vine grape growing stage, whereas higher temperatures during late spring are beneficial for the maturation stage. These findings led to the development of 2 linear regression models with the aim of forecasting Douro wine production at the early (March) and mid (July) season stages of the vine vegetative cycle. Both models perform well in terms of robustness and reliability. The results, using the mid season model, indicated that 2071-2100 climate scenarios (A2 and B2) favour an increase in wine production, due to the combined effects of temperature and precipitation in late spring and early summer.

\section{LITERATURE CITED}

Abrantes F, Rodrigues T, Montanari B, Santos C, Witt L, Lopes C, Voelker AHL (2011) Climate of the last millenium at the southern pole of the North Atlantic Oscillation: an innershelf sediment record of flooding and upwelling. Clim Res 48:261-280

Andrade A, Rubio B, Rey D, Alvarez-Iglesias P, Bernabeu AM, Vilas F (2011) Palaeoclimatic changes in the NW Iberian Peninsula during the last 3000 years inferred from diagenetic proxies in the Ría de Muros sedimentary record. Clim Res 48:247-259

Bode A, Anadón R, Morán XAG, Nogueira E, Teira E, Varela M (2011) Decadal variability in chlorophyll and primary production off NW Spain. Clim Res 48:293-305

Brands S, Herrera S, San-Martín D, Gutiérrez JM (2011a) Validation of the ENSEMBLES global climate models over southwestern Europe using probability density functions, from a downscaling perspective. Clim Res 48:145-161

Brands S, Taboada JJ, Cofiño AS, Sauter T, Schneider C (2011b) Statistical downscaling of daily temperatures in 
the NW Iberian Peninsula from global climate models: validation and future scenarios. Clim Res 48:163-176

Chust G, Borja Á, Caballero A, Irigoien X and others (2011) Climate change impacts on coastal and pelagic environments in the southeastern Bay of Biscay. Clim Res 48: 307-332

deCastro M, Gomez-Gesteira M, Ramos AM, Álvarez I, deCastro P (2011) Effects of heat waves on human mortality, Galicia, Spain. Clim Res 48:333-341

Drumond A, Nieto R, Gimeno L, Vicente-Serrano SM, LópezMoreno JI, Morán-Tejeda E (2011) Characterization of the atmospheric component of the winter hydrological cycle in the Galicia/North Portugal Euro-region: a Lagrangian approach. Clim Res 48:193-201

Gago J, Cabanas JM, Casas G, Miranda A (2011) Thermohaline measurements in the continental shelf zone of the NW Iberian Peninsula. Clim Res 48:219-229

Gómez-Gesteira M, Gimeno L, deCastro M, Lorenzo MN and others (2011) The state of climate in NW Iberia. Clim Res 48:109-144

Gouveia C, Liberato MLR, DaCamara CC, Trigo RM, Ramos AM (2011) Modelling past and future wine production in the Portuguese Douro Valley. Clim Res 48:349-362

> Hanemann M, Labandeira X, Loureiro ML (2011) Climate change, energy and social preferences on policies: exploratory evidence for Spain. Clim Res 48:343-348

Pardo PC, Padín XA, Gilcoto M, Farina-Busto L, Pérez FF (2011) Evolution of upwelling systems coupled to the longterm variability in sea surface temperature and Ekman transport. Clim Res 48:231-246

Ramos AM, Trigo RM, Santo FE (2011) Evolution of extreme temperatures over Portugal: recent changes and future scenarios. Clim Res 48:177-192

Rodríguez-Rajo FJ, Aira MJ, Fernández-González M, Seijo C, Jato V (2011) Recent trends in airborne pollen for tree species in Galicia, NW Spain. Clim Res 48:281-291

Santos F, Gómez-Gesteira M, deCastro M, Alvarez I (2011) Upwelling along the western coast of the Iberian Peninsula: dependence of trends on fitting strategy. Clim Res 48:213-218

Vicente-Serrano SM, López-Moreno JI, Drumond A, Gimeno L and others (2011) Effects of warming processes on droughts and water resources of the NW Iberian Peninsula (1930-2006). Clim Res 48:203-212 